\title{
Internet addiction among medical and non-medical students during COVID-19 pandemic, Tanta University, Egypt
}

\author{
Walaa M. Shehata ${ }^{1} \cdot$ Doaa E. Abdeldaim ${ }^{1}$ \\ Received: 14 April 2021 / Accepted: 13 June 2021 / Published online: 20 June 2021 \\ (C) The Author(s), under exclusive licence to Springer-Verlag GmbH Germany, part of Springer Nature 2021
}

\begin{abstract}
Internet addiction is one of the most growing addictive behaviors worldwide, especially among university students affecting their physical and mental health negatively. During COVID-19, accessing online books, completing assignments, and online assessments are highly recommended by universities, teachers, and students. The Internet has increasingly become a vital part of our lives, and distant online classes increase the dependency of students on the Internet. The aim of this study is to assess the level of internet addiction among medical or non-medical students in Tanta University, Egypt. This was a cross-sectional study conducted during October and November 2020. It included 373 students from the faculty of medicine and 373 non-medical students from the faculty of science. The validated (IAT-20) was used to assess the level of Internet addiction among these students. A total of $51.7 \%$ of medical students were found severe internet addicts and $43.4 \%$ of them were possible addicts compared to only $11.3 \%$ of non-medical students who were found severely addicted to the Internet and $68.9 \%$ of them were possible addicts with statistically significant difference between them. Female students of both colleges were found addicted to the Internet than males. Female medical and non-medical students suffered from severe Internet addiction more than non-medical and male ones. Appropriate awareness creation intervention strategies should be implemented to decrease the level of Internet addiction among university students and to reduce its harmful and negative consequences.
\end{abstract}

Keywords Internet $\cdot$ Addiction $\cdot$ Students $\cdot$ COVID-19 $\cdot$ Tanta, Egypt

\section{Introduction}

Since COVID-19 pandemic started and significant measures were taken worldwide to reduce the spread of the virus in the form of lockdowns of educational institutions and social avenues and keeping social distancing among people (Fernandes et al. 2020), these measures led to major changes in daily routine and activities of adolescents and adults and this in turn affected their psychological well-being (Fegert et al. 2020). Studies done in China (Wuhan), the first place of COVID19 virus, showed that people experienced the consequences

Responsible Editor: Lotfi Aleya

Doaa E. Abdeldaim

Doaam3y@gmail.com

Walaa M. Shehata

princesswalaa2008@yahoo.com

1 Public Health and Community Medicine Department, Faculty of Medicine, Tanta University, Tanta, Egypt of lockdown measures, like living a sedentary life and get involved in problematic use of the Internet as a way of escapism from these stressful events (Király et al. 2020).

Although proper use of the Internet is useful, its problematic use is usually resulting in undesirable consequences and even lead to a state of addiction. In general, addiction is a "compulsive need for and use of a habit-forming substance"; this state is characterized by tolerance and occurrence of physiological symptoms on withdrawal (Merriam-Webster's Dictionary 2019). Internet addiction (IA) is defined as "a kind of technology addiction and a behavioral addiction similar to a gambling habit" (Griffiths 2000).

This addiction is considered a psychological dependence on the use of the Internet which is characterized by excessive use, tolerance, craving, mood changes, and withdrawal symptoms on quitting (Mercy and Oluwatosin 2015; WHO 2015).

In October 2020, it was found that 4.66 billion persons were active Internet users, which forms about 59\% of the total world population. Ninety-one percent of those users accessed the Internet through mobiles. The highest number of Internet online users was found in Asia with more than 2.3 billion, and 
Europe was the second with about 728 million Internet users. UAE, Denmark, and South Korea were the highest countries in the Internet access rate (Johnson 2020).

In Egypt, the rate of Internet penetration was $54 \%$ with about 54.74 million Internet users were reported in January 2020. This number was increased by about $22 \%$ (9.8 million) from 2019 to 2020. Moreover, the number of social media users in Egypt also increased by about 7.3\% from 2019 to 2020 to reach approximately 42.00 million users (KEMP 2020).

However, the prevalence of problematic Internet use among college students has not been established, studies in the USA reported that $5-12 \%$ of university students in different colleges suffered from Internet addiction (Derbyshire et al. 2013). In Asia, the prevalence was $3.7 \%$ in India (Patil et al. 2017) and increased to $37 \%$ in Iraq and Malaysia (Babakr et al. 2019). In African countries, the range of prevalence was found from 5.1\% in Mauritius (Smita and Azhar 2018) and reach to $16.8 \%$ in Kenya (Maroma et al. 2019).

As Internet addiction increases among university students especially after the occurrence of COVID-19 pandemic, its negative physical, mental, and social consequences increase and affect their life and psychological well-being very badly (WHO 2015; Lee et al. 2019). These consequences may include lack of sleep, bad eating habits, psychological distress, depression, getting involved in other forms of addiction as smoking or alcohol use, and it may even reach to suicidal attempts. Also, problematic use of the Internet may lead to cognitive impairment and poor academic achievements (Salubi et al. 2018). Moreover, Internet addiction can lead to physical problems such as ophthalmic, hearing, musculoskeletal problems, and even thromboembolism (Lee et al. 2019).

The aim of this study was to assess the level of Internet addiction among medical or non-medical students in Tanta University, Egypt.

\section{Participants and methods}

\section{Study design: a cross-sectional study}

\section{Study population and sampling}

The study was conducted during October and November 2020 at the faculties of Medicine and Science, Tanta University, Egypt. Faculty of science was selected as an example of non-medical faculties in Tanta University. The students' numbers were enumerated and then the questionnaire was randomly distributed to the participants. Participants were selected through disproportionate probability stratified sampling technique. Study criteria included (a) fourth year students from both faculties and (b) students who were willing to participate.

\section{Sample size and sampling technique}

Prevalence of IA is $47 \%$ according to the results of a previous study conducted in Sohag Governorate among medical students in Sohag University (Ali et al. 2017) and with a precision of $5 \%$ and $95 \%$ confidence interval, 1.00 design effect, and power of study 0.8 ; a minimum sample size estimated was 380 subjects. The total sample size was 746: 373 students from faculty of medicine and 373 non-medical students from faculty of science. All the students were from fourth year. Sample size calculated by using Epi Info. The objectives of the study were explained to the students. The response rate was $98 \%$. This was a valid and reliable questionnaire (Cronbach's Alpha 0.88).

\section{Study tool}

A self-administered structured questionnaire consisted of two parts is used in this study. The first part included items on sociodemographic factors (age, gender, marital status, education, residence, and family income). The second part was Internet addiction test (IAT) originally developed by Dr. Kimberly Young (Young 1998). The IAT questionnaire has also been validated in various countries and has been used in some studies (Bahrainian et al. 2014; Krishnamurthy and Chetlapalli 2015). The IAT questionnaire is used as a screening tool to examine the level of Internet addiction. The questionnaire consisted of 20 items to examine symptoms of IA based on a 5-point Likert scale ranging from 0 to $5(0=$ not applicable, 1 = rarely, $2=$ occasionally, $3=$ frequently, $4=$ often, 5 = always). At last, the scores of all questions had been summed up and the level of Internet addiction was evaluated based on the final score. The severity of IA according to the IAT was as follows: $20-49$ points is "average Internet users"; 50-79 points is "possible problematic Internet users"; and 80100 points is "severe Internet addict with Internet usage causes significant problems in users life."

\section{Ethical considerations}

Approval from the ethical committee of Faculty of Medicine, Tanta University was obtained before conduction of the study. Objectives of the study were explained to all the included students. Confidentiality of collected data was confirmed to all participants. Informed oral consents were obtained from those willing to participate before continuing the study.

\section{Statistical analysis}

Statistical Package for Social Sciences (SPSS) (version 16.0, IBM, Armonk, NY) was used to analyze data of the study. Descriptive presentations were done for all variables of the 
study and comparison between groups was done by using Chisquare test. Level of significance was at $\mathrm{p}<0.05$.

\section{Results}

A total of 746 students completed the questionnaire; 373 nonmedical students were from the faculty of science (group I) and the same number was taken from the faculty of medicine (group II). Table 1 showed the sociodemographic data of the studied students. Most of respondents were females (64.3\% and $70 \%$ in groups I and II, respectively) and more than half of them are from urban areas. Ninety-two percent and $94.6 \%$ of both groups were not married. According to family income, more than half of them in both groups (53.4\% and 54.4\%, respectively) had just enough income. According to Table 2, most students reported often/always staying online longer than intended, neglecting their house chores and preferring excitement of the Internet than intimacy with their partner. Most respondents in both groups stated often/always their academic grades and their productivity were affected. A total of $41.6 \%$ of non medical students reported that at least occasionally they become defensive or secretive when anyone asked about their online presence, while $53.4 \%$ of medical students reported at least often defensive. They lost sleep at night due to Internet use in $44 \%$ and $64.1 \%$ in non-medical and medical students, respectively. More than four-fifths in both groups felt depressed or moody when they were offline. Table 3 illustrated that medical students were severely addicted to the Internet more than non-medical students with statistically significant difference between them with $68.9 \%$ of non-medical students were possible addicts to the Internet while $51.7 \%$ of medical students were severely addicted to the Internet. Table 4 shows the relation between the level of
Internet addiction and sociodemographic data of the studied groups. There was no significant difference between the level of Internet addiction and gender, residence, marital status, and family income.

\section{Discussion}

Internet addiction or problematic Internet use became a growing social and public health problem, affecting people worldwide (WHO 2015), especially teenagers and university students (Kuss and Lopez-Fernandez 2016) leading to many negative consequences (Lee et al. 2019).

The present study showed that the majority of medical students $(76.4 \%)$ reported at least often staying online longer than intended. This is quite similar to results reported by Taha et al. 2019, in their study in Qassim University, Saudi Arabia, as $70.8 \%$ of their medical students reported that they are staying at least often online longer than intended (Taha et al. 2019).

More than $75 \%$ of medical students in the current study neglected their household chores to spend more time online at least frequently. This is more than Taha et al. findings from their study in Saudi Arabia (52.7\%) (Taha et al. 2019) but these findings are much higher than those of a study done among Malaysian medical students with only $12.7 \%$ of students at least often neglected their household chores (Haque et al. 2016) and also more than another study done in Japan (Sato 2006).

The findings of current study on students' preferences to use the Internet over interaction with partners, colleagues, and friends were higher than findings of another studies conducted in Malaysia, Egypt, Kuwait, and India (Al-Menayes 2015; Saied et al. 2016; Patil et al. 2017).
Table 1 Sociodemographic data of the studied students

\begin{tabular}{llll}
\hline Sociodemographic data & Non-medical students & Medical students & $\begin{array}{l}\mathrm{X}^{2} \\
\mathrm{p}\end{array}$ \\
\hline Sex & & & \\
Male & $133(35.7 \%)$ & $112(30 \%)$ & $2.7(0.1)$ \\
Female & $240(64.3 \%)$ & $261(70 \%)$ & $5.7(0.02 *)$ \\
Residence & $205(55 \%)$ & $237(63.5 \%)$ & $2.1(0.1)$ \\
Urban & $168(45 \%)$ & $136(36.5 \%)$ & \\
Rural & & $20(5.4 \%)$ & \\
Marital status & $30(8 \%)$ & $353(94.6 \%)$ & \\
Married or engaged & $343(92 \%)$ & $17(4.6 \%)$ & \\
Not married & & $203(54.4 \%)$ & \\
Family income & $153(41 \%)$ & \\
Not enough & $199(53.4 \%)$ & & \\
Just enough & $150(40.2 \%)$ & & \\
Enough and saving & & & \\
\hline
\end{tabular}




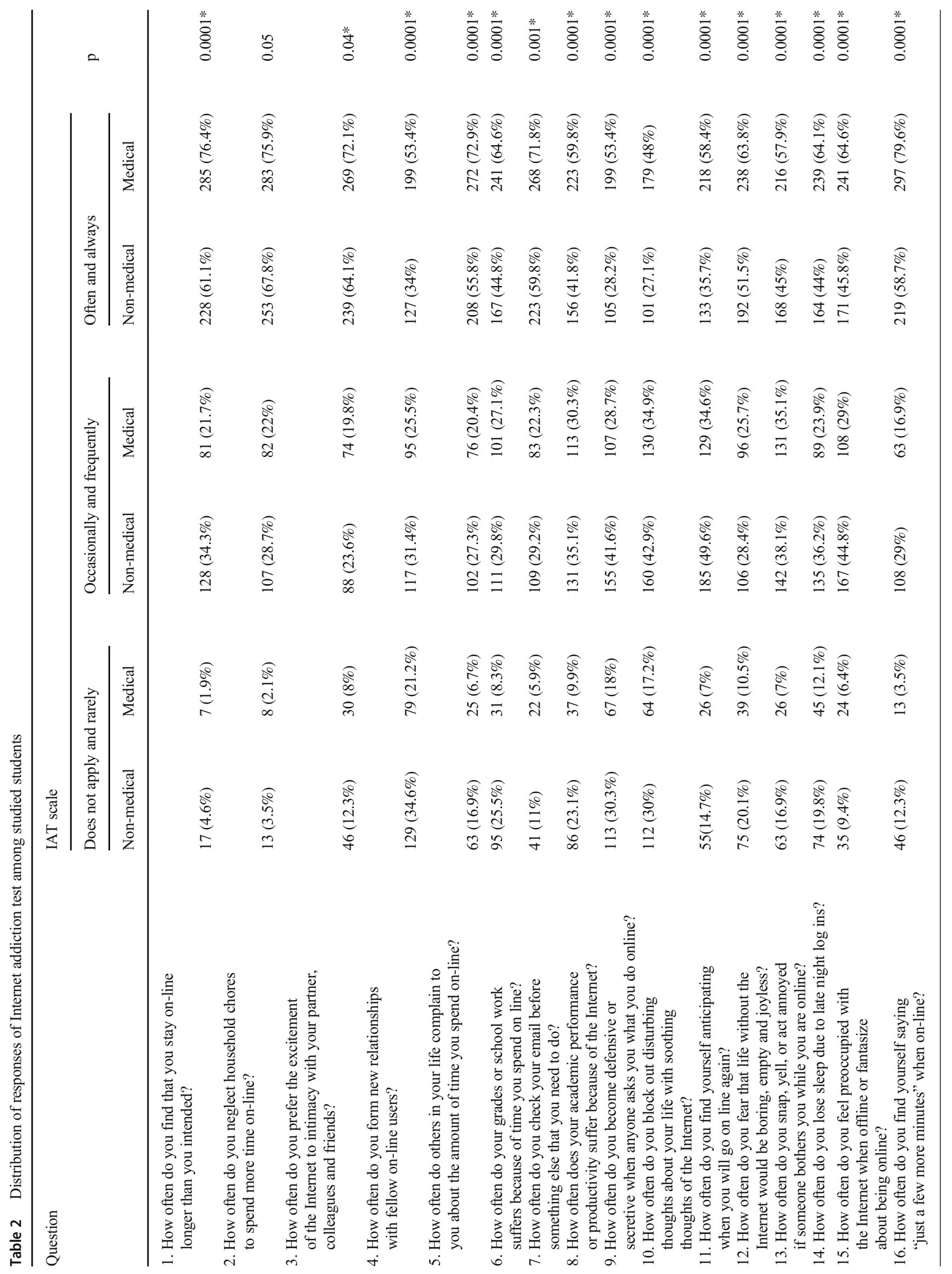


The majority of medical students in the present study received complaints from others because of spending long time using the Internet which is much higher than what was found by Haque et al. and Taha et al. as they found only one-quarter of their medical students got complaints (Haque et al. 2016; Taha et al. 2019).

The current study reported that $59.8 \%$ of medical students stated at least often their academic grades and their productivity were affected and $53.4 \%$ of them reported at least often become defensive when anyone asks you what you do online. Our results are higher than those of Taha et al.'s 2019 study (Taha et al. 2019). However, Haque et al. found much lower negative affection of academic performance of their medical students as only $12.1 \%$ of students reported that their academic performance was at least often affected by Internet use (Haque et al. 2016).

Regarding sleep, $64.1 \%$ of the medical students in the current study at least often lost night sleep because of late use of the Internet which is higher than those found by Taha et al. in their study (42.6\%) (Taha et al. 2019), while only $12.8 \%$ was found by Haque et al. 2016.

Moreover, the majority of our medical students $(86.6 \%)$ were found at least often depressed or moody when they were offline. This is higher than that found by Taha et al. 2019, as $60.7 \%$ of their included medical students felt at least frequently depressed when they are offline (Taha et al. 2019). These results were in line with findings from other studies done in Korea and India (Whang et al. 2003; Srijampana et al. 2014).

The present study found that $61.1 \%$ of non-medical students stay online longer than intended at least often, which was less than that found by Salubi et al. in their study in South African universities, as they found $71.3 \%$ of undergraduate students stay, at least often, on the Internet longer than intended (Salubi et al. 2018).

The current study found that more than half of the included medical students suffered from severe Internet addiction and $43.4 \%$ of them were possible addicts. High prevalence of severe Internet addiction may be attributed to easy access to the Internet as most people nowadays can access the Internet through their personal mobiles and also may be attributed to the occurrence of COVID-19 pandemic which increases the need to use the Internet to continuously check for its news, prevalence, and mortality rates and also may be due to lockdown measures and panic states that affect most people and urge them to overuse the Internet as an escaping mechanism.

These results are in contrary with Taha et al.'s findings of their study as they found that only $12.4 \%$ of medical students were severely addicted to the Internet while $57.9 \%$ of them were possible addicts (Taha et al. 2019). Moreover, Srijampana et al., in their study in India, found that only $0.4 \%$ of medical students were severe addicts to the Internet and $11.8 \%$ of them were possible addicts (Srijampana et al. 2014). 
Table 3 Level of Internet addiction among the studied students

\begin{tabular}{lllll}
\hline Level of Internet addiction & Non-medical students & Medical students & $X^{2}$ & P value \\
\hline Average Internet user & $74(19.8 \%)$ & $18(4.8 \%)$ & 15.7 & $0.000^{*}$ \\
Possible Internet addict & $257(68.9 \%)$ & $162(43.4 \%)$ & & \\
Severe Internet addict & $42(11.3 \%)$ & $193(51.7 \%)$ & & \\
\hline
\end{tabular}

Furthermore, Haque et al. in their Malaysian study did not found any of their students was severely addicted to the Internet and only $32 \%$ of them experienced occasional or frequent problems caused by their Internet use as they were possible addicts (Haque et al. 2016).

On comparing medical and non-medical students, the present study found that the medical students were severe Internet addicts $(51.7 \%)$ more than the non-medical ones $(11.3 \%)$ with statistically significant difference between them. This is in contrary with Soni et al.'s findings, as they found that medical students are less than students in faculty of engineering in Internet addiction (2.5\% of medical students and $12.5 \%$ of engineering students were severe internet addicts). However, they found that a similar percent of students in faculty of commerce $(2.5 \%)$ and none of students in faculty of art were severe Internet addicts (Soni et al. 2020).

Regarding the gender differences in Internet addiction, the present study found that female medical students were severely addicted to the Internet more than males $(71.5 \%$ of the severe Internet addicts were females compared to $28.5 \%$ that were males), which is consistent with the findings of Taha et al. in their study (Taha et al. 2019).

These findings were in contrary to the results of the study done in Tanzania by Mboya et al., as they found that males were Internet addicts more than females (Mboya et al. 2020) and also in contrary with Soni et al.'s findings from their study in India as they found that prevalence of Internet addiction among medical students was more among males than females (Soni et al. 2020).

Also, our findings were different from Srijampana et al.'s results as they found that males and females equally suffered from the Internet without any difference (Srijampana et al. 2014).

Regarding non-medical students; the present study also found that female students were more addicted to the Internet than male ones. This is in contrary with Soni et al.'s results in their study on arts, commerce, and engineering students as they found that male students in these 3 colleges were addicted to the Internet more than female students (Soni et al. 2020).

\section{Conclusions}

The current study observed that during the COVID-19 pandemic, Internet addiction was more prevalent among medical students than non-medical students with more than half of the medical students suffered from severe Internet addiction, which negatively affected their personal lives, their academic performances, and their night sleep. Also, our study revealed that female students, either medical or non-medical, suffered from Internet addiction more than male students. These results

Table 4 Relation between level of Internet addiction and sociodemographic data of the studied students

\begin{tabular}{|c|c|c|c|c|c|c|c|c|}
\hline \multirow[t]{2}{*}{ Sociodemographic data } & \multicolumn{6}{|c|}{ Level of Internet addiction } & \multirow[t]{2}{*}{$X^{2}$} & \multirow[t]{2}{*}{$P$ value } \\
\hline & \multicolumn{2}{|c|}{ Average Internet user } & \multicolumn{2}{|c|}{ Possible Internet addict } & \multicolumn{2}{|c|}{ Severe Internet addict } & & \\
\hline \multirow{3}{*}{$\begin{array}{l}\text { Sex } \\
\text { Male } \\
\text { Female }\end{array}$} & Non-medical & Medical & Non-medical & Medical & Non-medical & Medical & 4.5 & 0.1 \\
\hline & $25(33.8 \%)$ & $5(27.8 \%)$ & $98(38.1 \%)$ & $52(32.1 \%)$ & $10(23.8 \%)$ & $55(28.5 \%)$ & & \\
\hline & $49(66.2 \%)$ & $13(72.2 \%)$ & $159(61.9 \%)$ & $110(67.9 \%)$ & $32(76.2 \%)$ & $138(71.5 \%)$ & & \\
\hline \multicolumn{9}{|l|}{ Residence } \\
\hline Urban & $46(62.2 \%)$ & $9(50 \%)$ & $134(52.1 \%)$ & $110(67.9 \%)$ & $25(59.5 \%)$ & $118(61.1 \%)$ & 0.4 & 0.8 \\
\hline Rural & $28(37.8 \%)$ & $9(50 \%)$ & $123(47.9 \%)$ & $52(32.1 \%)$ & $17(40.5 \%)$ & $75(38.9 \%)$ & & \\
\hline \multicolumn{9}{|l|}{ Marital status } \\
\hline Married or engaged & $6(8.1 \%)$ & $2(11.1 \%)$ & $21(8.2 \%)$ & $9(5.6 \%)$ & $3(7.1 \%)$ & $9(4.7 \%)$ & 1.7 & 0.4 \\
\hline Not married & $68(91.9 \%)$ & $16(88.9 \%)$ & $236(91.8 \%)$ & $153(94.4 \%)$ & $39(92.9 \%)$ & $184(95.3 \%)$ & & \\
\hline \multicolumn{9}{|l|}{ Family income } \\
\hline Not enough & $4(5.4 \%)$ & $0(0 \%)$ & $13(5.1 \%)$ & $7(4.3 \%)$ & $7(16.7 \%)$ & $10(5.2 \%)$ & 11.6 & 0.6 \\
\hline Just enough & $35(47.3 \%)$ & $12(66.7 \%)$ & $147(57.2 \%)$ & $82(50.6 \%)$ & $17(40.5 \%)$ & $109(56.5 \%)$ & & \\
\hline Enough and saving & $35(47.3 \%)$ & $6(33.3 \%)$ & $97(37.7 \%)$ & $73(45.1 \%)$ & $18(42.9 \%)$ & $74(38.3 \%)$ & & \\
\hline
\end{tabular}


showed that compulsive use the Internet reaching to a state of severe addiction among university students was strongly attributed to worries of COVID-19 or as a symptom of depression, isolation, loneliness, or even escapism.

\section{Recommendations}

We recommend developing appropriate preventive, awareness, and intervention strategies to stop this excessive use of the Internet among university students and protect their physical and mental health from its harmful consequences. Students must be encouraged to use other recreational activities to help them to cope more appropriately with stress, panic, and isolation caused by such COVID-19 pandemic events.

Acknowledgements The authors would like to thank all students who participated in our study.

Author contribution The idea of this research was suggested by Walaa M. Shehata who wrote the intial protocol of this study and performed the fieldwork. Doaa E. Abdeldaim collected the data of the study, interpreted them and wrote the manuscript. Both authors reviewed the manuscript and approved its final version.

Data availability Not applicable.

\section{Declarations}

Consent to participate Not applicable.

Consent for publication Not applicable.

Conflict of interest The authors declare no competing interests.

\section{References}

Ali RA, Mohammed NA, Aly HY (2017) Internet addiction among medical students of Sohag University, Egypt. J Egypt Public Health Assoc 92(2):86-95

Al-Menayes JJ (2015) Dimensions of social media addiction among university students in Kuwait. Psychol Behav Sci 4:23-28

Babakr ZH, Majeed K, Mohamedamin P, Kakamad K (2019) Internet addiction in Kurdistan university students: prevalence and association with self-control. Eurasian J Educ Res 8(3):867-873

Bahrainian SA, Alizadeh KH, Raeisoon MR, Gorji OH, Khazaee A (2014) Relationship of internet addiction with self-esteem and depression in university students.J. Prev Med Hyg 55(3):86-89

Derbyshire KL, Lust KA, Schreiber LRN, Odlaug BL, Christenson GA, Golden DJ, Grant JE (2013) Problematic internet use and associated risks in a college sample. Compr Psychiatry 54(5):415-422

Merriam-Webster's Dictionary(2019). "addiction". From: https://www. merriam-webster.com/dictionary/addiction Accessed: Jan 2019.

Fegert JM, Vitiello B, Plener PL, Clemens V (2020) Challenges and burden of the Coronavirus 2019 (COVID-19) pandemic for child and adolescent mental health: a narrative review to highlight clinical and research needs in the acute phase and the long return to normality. Child Adolesc Psychiatry Ment Health 14:20

Fernandes B, Biswas UN, Tan-Mansukhani R, Vallejo A, Essau CA (2020) The impact of COVID-19 lockdown on internet use and escapism in adolescents. Revista de Psicología Clínica con Niños y Adolescentes 7(3):59-65

Griffiths M (2000) Does Internet and computer "addiction" exist? Some case study evidence. CyberPsychol Behav 3:211-218

Haque M, Rahman NA, Majumder MA, Haque SZ, Kamal ZM, Islam Z et al (2016) Internet use and addiction among medical students of Universiti Sultan Zainal Abidin, Malaysia. Psychol Res Behav Manag 9:297-307

Johnson J (2020). Worldwide digital population as of October 2020. Statista; Jan 27, 2021. Available at: https://www.statista.com/ statistics/617136/digital-population-worldwide/ accessed at 23.2. 2021

KEMP S (2020): DIGITAL 2020: EGYPT, Datareportal, 17 FEBRUARY 2020. https://datareportal.com/reports/digital-2020egypt\# Accessed at 23.2.2021

Király O, Potenza MN, Stein DJ, King DL, Hodgins DC, Saunders JB, Demetrovics Z (2020) Preventing problematic internet use during the COVID-19 pandemic: consensus guidance. Compr Psychiatry 100:152180

Krishnamurthy S, Chetlapalli SK (2015) Internet addiction: Prevalence and risk factors: a cross-sectional study among college students in Bengaluru, the Silicon Valley of India. Indian J Public Health 59: 115-121

Kuss DJ, Lopez-Fernandez O (2016) Internet addiction and problematic Internet use: a systematic review of clinical research. World J Psychiatry 6:143-176

Lee S-Y, Kim MS, Lee HK (2019) Prevention strategies and interventions for internet use disorders due to addictive behaviors based on an integrative conceptual model. Curr Addict Rep 6(3):303-312

Maroma FO, Karega M, Oteyo JS (2019) Relationship between depression and pathological internet use among university students. Cypriot J Educ Sci 14(2):201-207

Mboya IB, Leyaro BJ, Kongo A, Mkombe C, Kyando E, George J (2020) Internet addiction and associated factors among medical and allied health sciences students in northern Tanzania: a cross-sectional study. BMC Psychology 8:73

Mercy ON, Oluwatosin BO (2015) Internet addiction among undergraduates in University of Ibadan: imperative for counselling intervention. Afr J Psychol Stud Soc Issues 18(3):1-14

Patil SD, Deshmukh JS, Dagdiya KR (2017) Prevalence and pattern of internet addiction among medical students in Nagpur, Maharashtra. Int J Community Med Public Health 4:2412-2416

Saied SM, Elsabagh HM, El-Afandy AM (2016) Internet and Facebook addiction among Egyptian and Malaysian medical students: a comparative study, Tanta University, Egypt. Int J Community Med Public Health 3:1288-1297

Salubi OG, Nekhwevha F, Oyediran-Tidings S, Ondari-Okemwa E (2018) Digital media usage and prevalence of internet addiction among undergraduate students in South Africa. Int J Web Appl 10(4):127-136

Sato T (2006) Internet addiction among students: prevalence and psychological problems in Japan. Japan Med Assoc J 49:279-283

Smita G, Azhar F (2018) Prevalence and characteristics of internet addiction among university students in Mauritius. SM J Case Rep 4(1): 1077

Soni K, Alam MN, Joshi PR, Kaore NM, Singh SP (2020) Comparative evaluation of internet addiction amongst arts, commerce, engineering and medical students. Int J Community Med Public Health 7: 3197-3201

Srijampana VVGR, Endreddy AR, Prabhath K, Rajana B (2014) Prevalence and patterns of internet addiction among medical students. Med J Dr DY Patil Univ 7:709-713 
Taha MH, Shehzad K, Alamro AS, Wadi M (2019) Internet use and addiction among medical students in Qassim University, Saudi Arabia. Sultan Qaboos University Med J, Vol. 19. Iss. 2:e142-e147

Whang LS, Lee S, Chang G (2003) Internet over-users' psychological profiles: a behavior sampling analysis on Internet addiction. CyberPsychol Behav 6:143-150

WHO (2015). Public health implications of excessive use of the internet, computers, smartphones and similar electronic devices: meeting report, Main Meeting Hall, Foundation for Promotion of Cancer
Research, National Cancer Research Centre, Tokyo, Japan, 27-29 2014. Geneva: World Health Organization; 2015.

Young K (1998) Internet addiction: the emergence of a new clinical disorder. Cyber Psychol Behav 1(3):237-244

Publisher's note Springer Nature remains neutral with regard to jurisdictional claims in published maps and institutional affiliations. 